\title{
Modulating immunometabolism of tumor specific mouse and human lymphocytes to enhance T cell based therapy for cancer
}

\author{
Madhusudhanan Sukumar ${ }^{1 *}$, Jie Liu², Shashank J Patel ${ }^{3}$, Christopher A Klebanoff ${ }^{1}$, Gautam Mehta², \\ Rahul Roychoudhuri', Joseph Crompton ${ }^{1}$, David Clever ${ }^{1}$, Luca Gattinoni ${ }^{4}$, Pawel Muranski ${ }^{5}$, Toren Finkel ${ }^{5}$, \\ Nicholas Restifo ${ }^{1}$
}

From 30th Annual Meeting and Associated Programs of the Society for Immunotherapy of Cancer (SITC 2015) National Harbor, MD, USA. 4-8 November 2015

Tumor cells and tumor infiltrating lymphocytes (TIL) competes for glucose and other metabolites within the tumor microenvironment for their survival. Glucose consumption by tumors metabolically restricts $\mathrm{T}$ cell's ability to produce effector cytokines and therefore approaches to improve the overall metabolic fitness of TIL may improve tumor regression in cancer patients. Long-term survival and anti-tumor immunity critically depends on their metabolic fitness but approaches to select metabolically robust $\mathrm{T}$ cells for adoptive immunotherapy remains less clear. Here we introduce a simple and clinically translatable method using a lipophilic cationic dye (tetramethylrhodamine methyl esterTMRM) to identify and isolate metabolically-robust $\mathrm{T}$ cells based on mitochondrial membrane-potential $(\Delta \Psi \mathrm{m})$. Cells with lower membrane-potential (low$\Delta \Psi \mathrm{m})$ had a molecular profile characteristic of memory precursors and displayed an enhanced ability to enter the memory pool as compared to cells displaying higher mitochondrial potential (high- $\Delta \Psi \mathrm{m}$ ) characteristic of short-lived effectors. Interestingly, we also found that multiple distinct negative inhibitory receptors such as programmed death-1 (PD-1), cytotoxic T-lymphocyteassociated protein 4 (CTLA-4), B- and T-lymphocyte attenuator (BTLA), Lymphocyte-activation gene 3 (LAG-3) and T cell immunoglobulin mucin receptor 3 (TIM-3) were enriched in the high- $\Delta \Psi \mathrm{m}$ subset compared to the low- $\Delta \Psi \mathrm{m}$ subset. Comprehensive metabolomic and gene expression profiling demonstrated global features of metabolic fitness in low $\Delta \Psi \mathrm{m}$ sorted $\mathrm{CD} 8^{+}$

${ }^{1}$ Center for Cancer Research, NCI/NIH, Bethesda, MD, USA

Full list of author information is available at the end of the article
$\mathrm{T}$ cells-including reduced glycolysis, enhanced fattyacid oxidation and robust spare respiratory capacity. Transfer of low- $\Delta \Psi \mathrm{m} T$ cells was associated with superior long-term in vivo persistence as evidenced by 100 fold increase in the frequency of $\mathrm{T}$ cells 300 days after adoptive transfer, augmented autoimmunity and an enhanced capacity to eradicate established cancer compared with high- $\Delta \Psi \mathrm{m}$ cells. High- $\Delta \Psi \mathrm{m} T$ cells exhibited elevated ROS levels, increased effector cytokines and had up-regulation of genes involved in DNA replication, DNA repair and cell-cycle arrest genes compared to low- $\Delta \Psi \mathrm{m} T$ cells. Surprisingly, use of $\Psi \mathrm{m}$ to enrich for cells with superior metabolic features was observed within central-memory $\left(\mathrm{T}_{\mathrm{CM}}\right)$ and effector (Tc17, Th1, Th17) $\mathrm{T}$ cells as well as long-term hematopoietic stem cells (LT-HSC). Finally, we also demonstrate that mitochondrial membrane potential based sorting can identify $\mathrm{CD}^{2} 5 \mathrm{RO}^{-} \mathrm{CCR}^{+}$human $\mathrm{CD}^{+} \mathrm{T}$ cells. These findings demonstrate that metabolic-sorting serves as a complementary strategy to the use of conventional cell surface markers for identifying cells with the capacity for longterm survival and ongoing effector function after adoptive-transfer. This novel metabolism-based approach may be broadly applicable to therapies involving transfer of hematopoietic stem cells or lymphocytes for treatment of viral-associated illnesses and advanced cancer.

\footnotetext{
Authors' details

${ }^{1}$ Center for Cancer Research, NCI/NIH, Bethesda, MD, USA. ${ }^{2}$ National Institutes of Health, Rockville, MD, USA. ${ }^{3}$ Center for Cancer Research, $\mathrm{NCl}$ / $\mathrm{NIH}$, Rockville, MD, USA. ${ }^{4}$ Experimental Transplantation and Immunology Branch, NCI/NIH, Bethesda, MD, USA. ${ }^{5} \mathrm{NIH}$, Bethesda, MD, USA.
} 


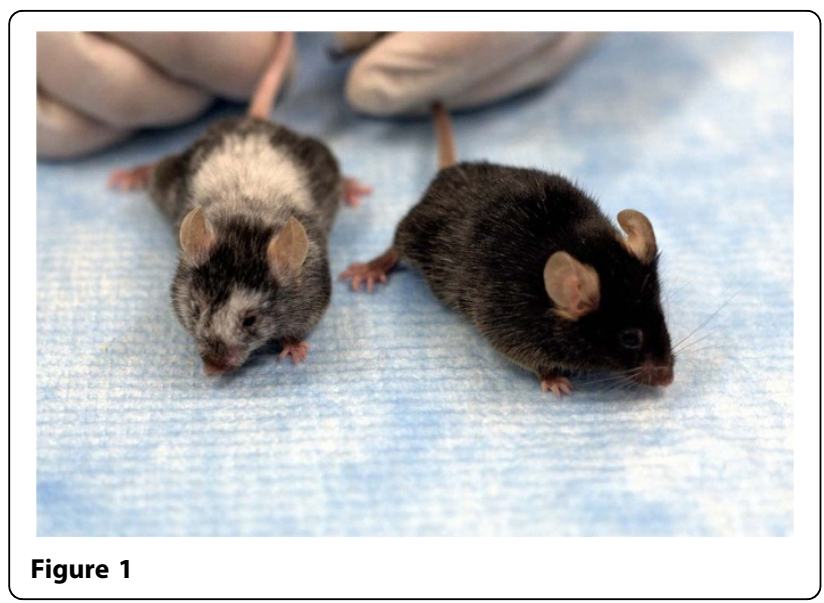

Published: 4 November 2015

doi:10.1186/2051-1426-3-S2-P325

Cite this article as: Sukumar et al.: Modulating immunometabolism of tumor specific mouse and human lymphocytes to enhance T cell based therapy for cancer. Journal for ImmunoTherapy of Cancer 2015 3(Suppl 2): P325.
Submit your next manuscript to BioMed Central and take full advantage of:

- Convenient online submission

- Thorough peer review

- No space constraints or color figure charges

- Immediate publication on acceptance

- Inclusion in PubMed, CAS, Scopus and Google Scholar

- Research which is freely available for redistribution

Submit your manuscript at www.biomedcentral.com/submit
C Biomed Central 